\title{
EDUCAÇÃO E PATRIMÔNIO CULTURAL: UMA ENCRUZILHADA NAS POLÍTICAS PÚBLICAS DE PRESERVAÇÃO
}

\section{FERNANDO PASCUOTTE SIVIERO}

Escola Politeia, São Paulo, São Paulo, Brasil

DOI: http://dx.doi.org.br/10.11606/issn.1980-4466.v0i19p80-108

\section{RESUMO}

Este artigo apresenta uma análise crítica da educação na trajetória do Instituto do Patrimônio Histórico e Artístico Nacional (Iphan) entre 1937 e 2014. Ações educativas estiveram presentes desde a sua fundação, embora sempre tivessem concepções, formas e funções heterogêneas e diversas. Ao estudar os lugares e as funções da educação na política preservacionista nacional, busca-se compreender como o Estado entendia e se relacionava com a sociedade na preservação dos bens culturais. A educação patrimonial surgiu em meados da década de 1980 como uma metodologia pedagógica para monumentos e objetos museográficos. Atualmente assiste-se ao surgimento de uma concepção dialógica, transversal e coletiva de educação patrimonial que almeja aproximar o campo do patrimônio cultural da sociedade civil. Faz-se necessário portanto conhecer essa trajetória para acompanhar criticamente as formas como a educação é praticada pelo Iphan e fortalecer o patrimônio cultural como instrumento político e direito social.

\section{PALAVRAS-CHAVE}

Patrimônio cultural. Educação. História. 


\section{EDUCATION AND CULTURAL HERITAGE: CROSSROADS IN PUBLIC HERITAGE POLICIES}

FERNANDO PASCUOTTE SIVIERO

Escola Politeia, São Paulo, São Paulo, Brasil

DOI: http://dx.doi.org.br/10.11606/issn.1980-4466.v0i19p80-108

\section{ABSTRACT}

This article presents a critical analysis of education in Iphan's (Historical and Artistic National Heritage Institute) trajectory from 1937 to 2014. Educational activities were developed and offered since its founding, even though under diverse and heterogeneous conceptions, functions and forms through time. The study of the functions of education in national heritage policies will be pursued in order to comprehend how the State used to understand and relate with society to protect cultural assets. Heritage education emerged in the mid-1980s as a pedagogical methodology focused on monuments and museographic objects. Today, it is possible to observe a dialogical, transversal and collective conception of heritage education emerging, one that intents to bring the cultural heritage field closer to society. Therefore, it is necessary to know this trajectory so we can follow in a discerning way how IPHAN practices education and so we can strengthen cultural heritage as a political instrument and a social right.

\section{KEYWORDS}

Cultural heritage. Heritage education. History. 


\section{INTRODUÇÃO: O PONTO DA ENCRUZILHADA}

Este artigo pretende analisar a história da educação dentro do Instituto Nacional do Patrimônio Histórico e Artístico Nacional (Iphan) entre 1937 e 2014, tendo no horizonte do debate a inserção das ações preservacionistas no espaço social urbano e sua interferência na materialidade e na realidade social - nas práticas e relações sociais, nas relações simbólicas e afetivas e nas subjetividades. Observa-se há algumas décadas que intervenções em conjuntos urbanos tombados vêm transformando a política preservacionista em um instrumento político de esquecimento e limpeza social (processos de gentrificação) (LEITE, 2007). Por outro lado, assiste-se também a uma ampliação do uso do patrimônio cultural como um direito social, ou seja, como política pública estratégica para grupos interessados e envolvidos em diversas querelas e tensões socioespaciais contemporâneas.

Contudo, a política preservacionista brasileira (em seus três níveis federativos) opera através de conceitos, concepções, metodologias e mecanismos técnicos, jurídicos e administrativos que excluem e alijam a sociedade civil da maior parte dos processos decisórios sobre a identificação, valoração e preservação dos seus bens culturais. Nessa lógica, empregada há quase 80 anos, resta à "população em geral" aceitar - e agradecer, se possível -, as definições, escolhas e consequentes interferências da política preservacionista em sua vida. 
A forma autoritária, especializada e autorizada como o tombamento é realizado e repercutido gera perturbações de várias ordens em comunidades e detentores dos bens culturais, provocando tensões cujas soluções, na história dessa instituição, quase sempre recaíram sobre a ação educativa. Por que os detentores dos bens culturais e a sociedade em geral não contribuem para a preservação de algo que é tão importante para si? Não querem preservar sua própria identidade? Por que insistem em querer alterar ou destruir algo que deve ser preservado? Seria falta de educação ou de cultura? Por que o povo brasileiro menospreza seu passado e valoriza tanto a modernidade, o novo e aquilo de vem de fora?

Essas questões orientam o discurso daqueles que se envolvem e realizam a preservação de bens culturais. É comum encontrar nos ambientes preservacionistas defesas enfáticas sobre a necessidade de conscientizar, educar e instruir a população para a preservação de seus bens culturais. O que quase não se discute é como Estado e a população constroem, reconhecem e usam seus bens culturais (e sonham seu futuro). Podemos então reformular as questões acima, sob outra perspectiva: até que ponto os bens reconhecidos como patrimônios culturais representam os diferentes grupos sociais que os detêm? De que modo a política preservacionista contribui com os fenômenos de segregação, exclusão e discriminação social?

Olhar criticamente a trajetória da educação no Iphan significa, portanto, compreender como o Estado vem pautando sua relação com a população nesse campo e levantar subsídios para lutar por outras formas.

A educação se faz presente ao longo de toda a história da política preservacionista brasileira. De acordo com a pedagoga e arquiteta Cléo de Oliveira (2011), ela sempre foi uma atividade complementar, mas fundamental às outras ações desenvolvidas pelo Iphan. Essa ambiguidade justifica o caráter empírico, pontual, emergencial e informativo que a educação vem sendo tratada no campo do patrimônio.

A ideia de que "[...] só se preserva o que se conhece" (OLIVEIRA, 2011, p. 3) fundamenta a crença na intrínseca relação entre conhecer e preservar que transformou a educação em um instrumento de mediação do Estado com a sociedade desde a fundação do Iphan. Sob tal máxima, a práxis educativa do Iphan assumiu diferentes formas e funções ao longo do tempo.

Mesmo complementar e secundária, a educação é uma arena silenciosa 
de disputas teóricas e práticas pouco conhecida, destrinchada e debatida no contexto institucional. O pouco acúmulo teórico observado até $2004 \mathrm{em}$ contraposição às ações recorrentes marcava um (não) lugar da educação dentro das práticas preservacionistas brasileiras.

\section{O (NÃO) LUGAR DA EDUCAÇÃO NO IPHAN}

Ao buscar indícios e discursos sobre a educação na história do Iphan, se depara inevitavelmente com as três figuras míticas de sua trajetória: Mário de Andrade, Rodrigo Melo Franco de Andrade e Aloísio Magalhães.

O autor de Macunaíma destaca-se nessa trajetória pela elaboração, em 1936, do anteprojeto para constituição de um serviço de proteção aos monumentos nacionais ${ }^{1}$. Nesse período, Mário de Andrade era diretor do recém-criado Departamento de Cultura do Município de São Paulo e iniciava seus trabalhos nas políticas públicas influenciado por suas viagens etnográficas no norte e nordeste do Brasil e pela corrente culturalista da antropologia norte-americana (Boas, Redfield e Herskovits) ${ }^{2}$.

Mesmo profundamente alterado ${ }^{3}$, o anteprojeto para o Serviço do Patrimônio Artístico Nacional (Span) foi um marco na política preservacionista brasileira, (re)visitado inúmeras vezes na própria história da instituição devido à sua abordagem antropológica ${ }^{4}$. De acordo com Mário Chagas, esse anteprojeto apresentava "[...] um sistema de classificação octogonal, no qual o termo arte (rimas à parte) era apenas a entrada principal para oito categorias distintas" (CHAGAS, 1998, p. 99). Dentro dessa concepção, não havia hierarquia de valores entre as oito categorias e o conceito de patrimônio abrangia tanto os bens materiais quanto os imateriais.

Os bens artísticos nacionais tombados seriam organizados em quatro livros de tombo e em quatro museus nacionais correspondentes. Haveria, portanto, um livro e um museu "Arqueológico e Etnográfico" e outro "Histórico"; um "Livro de Tombo das Belas Artes" atrelado à "Galeria

\footnotetext{
1. Esse anteprojeto serviu de base para a formulação do Decreto-lei no 25/1937 que instituiu o Sphan e a política preservacionista nacional. Esse documento pode ser visto na íntegra em ANDRADE, 2002, p. 271-287.

2. RUBINO, 2002, p.145-146.

3. Sobre as alterações entre o anteprojeto de Mário de Andrade e o Decreto-lei no 25/1937, veja: CHAGAS, 1998, p. 98-106.

4. SILVA, 2002, p.129-137.
} 
Nacional de Belas Artes"; e um "Livro de Tombo das Artes Aplicadas" vinculado ao "Museu de Artes Aplicadas e Técnica Industrial”. Os museus foram pensados como espaços para exposição das obras de arte "[...] colecionadas para cultura e enriquecimento do povo brasileiro pelo Governo Federal" (ANDRADE, 2002, p. 277); enquanto os livros de tombo, como fonte de pesquisa e conhecimento. Para Andrade, museus e livros de tombo eram canais de proteção, difusão e promoção do patrimônio artístico nacional.

Através da ideia de enriquecimento da cultura brasileira (pela preservação de suas obras de arte) e do povo brasileiro (pela promoção do conhecimento de sua cultura), Mário de Andrade vinculou difusão e promoção à educação, apontando assim uma possível função educativa do patrimônio: informar, fazer conhecer. Como a escolha do que deveria ser valorizado como patrimônio estaria nas mãos do Span, a educação seria uma ferramenta de legitimação e difusão dos valores atribuídos pelo Estado a um conjunto autorizado de bens.

A única referência explícita à educação no anteprojeto encontra-se na resposta à quarta objeção "Por que o quarto museu é chamado Museu de Artes Aplicadas e Técnica Industrial? Então a técnica industrial é uma arte?”: Arte é uma palavra geral, que neste seu sentido geral significa a habilidade com que o engenho humano se utiliza da ciência, das coisas e dos fatos. Isso foi aproveitado para preencher uma feia lacuna do sistema educativo nacional, a meu ver, que é a pouca preocupação com a educação pela imagem, o sistema talvez mais percuciente de educação. Os livros didáticos são horrorosamente ilustrados; os gráficos, mapas, pinturas das paredes das aulas são pobres, pavorosos e melancolicamente pouco incisivos; o teatro não existe no sistema escolar; o cinema está em três artigos duma lei, sem nenhuma ou quase sem nenhuma aplicação. Aproveitei a ocasião para lembrar a criação dum desses museus técnicos que já estão se espalhando regularmente no mundo verdadeiramente em progresso cultural. Chamam-se hoje mais ou menos universalmente assim os museus que expõem os progressos de construção e execução das grandes indústrias, e as partes de que são feitas, as máquinas inventadas pelo 
homem. São museus de caráter essencialmente pedagógico. Os modelos mais perfeitos geralmente citados são o Museu Técnico de Munich e o Museu de Ciência e Indústria de Chicago. (ANDRADE, 2002, p. 279)

O que seria o caráter pedagógico desse museu? Mário de Andrade explica-o utilizando como exemplo uma possível "Sala do Café”, onde estariam expostos todo o processo de cultivo, produção, comercialização e consumo desse produto. A exposição deveria ter toda sorte de objetos e informações visuais disposta em diferentes suportes: fotografias, gráficos estatísticos, desenhos comparativos etc. Esse mesmo modelo de exposição deveria ser aplicado às outras indústrias para que o público visitante tivesse a oportunidade de conhecer as artes aplicadas nacionais e estrangeiras que constituíram a cultura brasileira.

Focada nas técnicas (saber fazer) circunscritas aos principais ciclos econômicos da história nacional (açúcar, ouro, café, borracha) às indústrias locais (algodão, lã, boi, carnaúba, ferro, laranja) e às importadas (avião, locomotiva, imprensa etc.), essa museografia retrata a perspectiva antropológica andradiana da história e da arte nacional. Por meio desse museu e do seu caráter pedagógico, buscar-se-ia a valorização dos conhecimentos do mundo do trabalho que não eram, naquele contexto, considerados expressão social e cultural do povo brasileiro.

Diante da perspectiva pedagógica conferida ao Museu de Artes Aplicadas e Técnica Industrial é possível perceber que esse artista e intelectual paulistano compreendia a arte e sua preservação por um viés culturalista, e a educação como transmissão do legado cultural nacional. Desse modo, a difusão da arte nacional seria uma prática de caráter educativo fundamental à sua preservação.

Para além do anteprojeto, Mário de Andrade foi técnico e colaborador da Seção Regional de São Paulo do Serviço do Patrimônio Histórico e Artístico Nacional (Sphan), em períodos irregulares, entre 1937 e 1945 (ano de sua morte). Nesses momentos, produziu, entre outras coisas, dois artigos para 
a Revista do Patrimônio Histórico e Artístico Nacional5 e uma monografia 6 .

Essa produção sinaliza uma prática fortemente incentivada por Rodrigo Melo Franco de Andrade durante a denominada fase heroica do Sphan’: o desenvolvimento e divulgação de pesquisas, monografias e artigos técnicos sobre história da arte e da arquitetura brasileira e sobre preservação dos monumentos históricos e artísticos nacionais. O antropólogo José Reginaldo Santos Gonçalves (2002) destaca que, entre as narrativas utilizadas por esse jornalista para justificar a existência e a atuação do Sphan, encontra-se a ideia da perda do patrimônio nacional (desaparecimento, dispersão e destruição):

Ele crê [...] que o fator principal no processo de desaparecimento do patrimônio histórico e artístico nacional é a “indiferença da população" em relação à importância da defesa e preservação desse patrimônio. Indiferença, segundo ele, partilhada não apenas “...pelas massas pouco esclarecidas da população brasileira...”, mas, igualmente, pelas “...classes mais favorecidas e que se presumem cultas" (ANDRADE, [1969] 1987, p.182). Associada a esse diagnóstico está, evidentemente, a ênfase presente no discurso de Rodrigo na tarefa de "educar" a população a respeito dos valores representados pelo patrimônio nacional. (GONÇALVES, 2002, p. 93)

Ao afirmar que a ignorância e indiferença da população com seu patrimônio histórico e artístico eram a grande "inimiga" da preservação - sem observar o contexto socioeconômico e as condições de vida daqueles que viviam próximos ou detinham esses bens -, Rodrigo Melo Franco de Andrade estabeleceu uma relação direta, intrínseca e mecânica entre conhecer (educação) e preservar, como pode ser atestado neste discurso da década de 1960:

Em verdade, só há um meio eficaz de assegurar a defesa permanente do patrimônio de arte e de história do país:

\footnotetext{
5. ANDRADE, 1937; 1941.

6. ANDRADE, 1945 .

7. Maria Cecília Londres Fonseca denomina assim o período entre 1937 e 1967, fase marcada pela direção do jornalista mineiro Rodrigo Melo Franco de Andrade (FONSECA, 1997).
} 
é a da educação popular. Ter-se-á de organizar e manter uma campanha ingente visando a fazer o povo brasileiro compenetrar-se do valor inestimável dos monumentos que ficaram do passado. (ANDRADE, 1987, p. 64)

Ao analisar o discurso transcrito acima, percebe-se que a população brasileira (ente abstrato) seria o público-alvo de ações educativas que transmitiriam as informações e os valores definidos pelo Sphan sobre história e arte nacionais. Assim, o sucesso pedagógico seria o (re)conhecimento por parte da população da importância coletiva de preservar os bens históricos e artísticos escolhidos pelo Estado. Acredita-se, desde então, que tal reconhecimento é a base para a apropriação, contemplação e preservação dos monumentos nacionais. Essa perspectiva educativa era, portanto, coerente e condizente com a concepção de patrimônio nacional e mantinha a lógica paternalista que sustenta(va) a relação entre Estado e sociedade.

Nesse sentido, podemos entender que a produção e a difusão de conhecimentos na fase heroica foram vistas como uma prática com pretensões educativas. No texto de abertura do primeiro volume da revista, intitulado "Programa", o então diretor do Sphan afirmou querer com essa publicação "[...] divulgar os conhecimentos dos valores de arte e de história que o Brasil possui com a intenção de contribuir para seu estudo" (ANDRADE, 1937, p. 3). Além disso, ele via a revista como uma resposta à ignorância e indiferença do povo brasileiro com seus bens históricos e artísticos nacionais:

[...] ninguém contestará, no entanto, que há necessidade de uma ação sistemática e continuada com o objetivo de dilatar e tornar mais seguro e apurado o conhecimento dos valores de arte e de história de nosso país. A tendência entre nós, quando se trata desses assuntos, é descambar para um gênero de literatura impróprio para o estudo objetivo das questões que há a esclarecer. Essa balda pouco apreciável nos tem feito perder um tempo precioso, que cumpre recuperar.

A criação da Revista do Serviço do Patrimônio Histórico e Artístico Nacional visa contribuir para este efeito. Sem pretensões a estampar trabalhos definitivos ou completos, 
uma vez que, a certos respeitos, os estudos daquela natureza se acham ainda no Brasil numa fase quase primária, esta publicação procurará corresponder ao fim a que se destina. (ANDRADE, 1937, p. 3-4)

Embora vislumbrasse tais funções à revista, não é possível acreditar que num país eminentemente analfabeto - como o Brasil das décadas de 1940, 50, 60... - a publicação de revistas e monografias especializadas alcançasse, em curto e em médio prazos, objetivos tão complexos como os apontados na citação anterior. No entanto, as publicações do Sphan contribuíram para consolidar a produção e o debate de conhecimento sobre arte e patrimônio no Brasil.

Tal concepção de patrimônio histórico, assim como da educação para o patrimônio, estava em acordo com as cartas patrimoniais do momento - como a Carta de Atenas, de 1931, Carta de Nova Délhi, de 1956, e as Cartas de Paris, da década de 1960. Na primeira carta internacional encontra-se o senso comum da educação na práxis preservacionista. A relação população-informação-conservação/preservação é tratada como óbvia, natural e direta; e, por isso a educação, considerada ferramenta para difusão do conhecimento, é apontada como necessária para a preservação e conservação do patrimônio.

b) O papel da educação e o respeito aos monumentos: A conferência, profundamente convencida de que a melhor garantia de conservação de monumentos e obras de arte vem do respeito e do interesse dos próprios povos, considerando que esses sentimentos podem ser grandemente favorecidos por uma ação apropriada dos poderes públicos, emite o voto de que os educadores habituem a infância e a juventude a se absterem de danificar os monumentos, quaisquer que eles sejam, e lhes façam aumentar o interesse de uma maneira geral, pela proteção dos testemunhos de toda a civilização. (CARTA DE ATENAS, 1931, apud OLIVEIRA, 2011, p. 74)

A relação que se defende entre população e monumento é a de respeito e contemplação, atitudes que garantiriam a preservação de sua materialidade 
e, por consequência, de seus valores. Informar, nesse contexto, significa oferecer as informações necessárias para se criar respeito. A educação, portanto, seria uma ferramenta de verticalização e institucionalização de uma narrativa particular e da relação entre a população e seus monumentos.

Embora os Andrades concordassem em teoria que a função da educação na práxis preservacionista era a transmissão do legado cultural nacional, observa-se uma profunda diferença nos objetivos dessa ação educativa. Para o escritor e músico paulistano, a difusão do patrimônio artístico nacional deveria enriquecer culturalmente o povo brasileiro, ao passo que, para o jornalista e advogado mineiro, a educação deveria colaborar diretamente na preservação do patrimônio nacional - evitar a mutilação, o desaparecimento e a perda dos monumentos nacionais. Em ambos os discursos, a prática educativa na preservação do patrimônio aproximava-se de uma concepção de educação denunciada como bancária, anos mais tarde, por Paulo Freire: Na visão "bancária" da educação, o "saber" é uma doação dos que se julgam sábios aos que julgam nada saber. Doação que se funda numa das manifestações instrumentais da ideologia da opressão - a absolutização da ignorância, que constitui o que chamamos de alienação da ignorância, segundo a qual esta se encontra sempre no outro. (FREIRE, 2005, p. 67)

Essa diferença pedagógica é um reflexo da mudança conceitual entre Span e Sphan e aponta funções distintas para o Estado na preservação do patrimônio nacional. A ideia central era "colecionar" monumentos para contemplação e para construção simbólica da identidade nacional como povo civilizado ${ }^{8}$. Nesse sentido, colaborar na preservação dos monumentos nacionais tombados era um ato cívico. A relação de pertencimento, o sentimento de identidade ou a função memorial - questões caras aos debates sobre educação patrimonial nos dias de hoje -, interessava na medida em que contribuía e/ou confirmava a narrativa oficial que atribuía aos bens o título de patrimônio histórico e artístico nacionais.

Com a morte de Rodrigo Melo Franco de Andrade no final da década

8. Os bens históricos e artísticos nacionais eram considerados monumentos que carregavam em sua materialidade valores artísticos e históricos que remetiam à tradição nacional brasileira ao mesmo tempo que a inseria no hall dos países civilizados (GONÇALVES, 2002, p. 94). 
de 1960, Renato Soeiro assumiu a direção do Sphan, dando início, de acordo com Fonseca (1997), à fase moderna desse órgão. Para esse debate, suas ações podem ser entendidas como uma continuidade. Seu esforço em descentralizar a política preservacionista pelos estados e municípios da federação e implantar o Programa Integrado de Reconstrução das Cidades Históricas (PCH), lançado em 1973, não alteraram o entendimento e o lugar da educação no campo preservacionista.

Contudo, a partir da direção de Aloísio Magalhães, entre 1979 e 1982, observa-se um processo de profundas perturbações na estrutura, nos conceitos e nas formas de operar a preservação do patrimônio no Brasil. O Iphan se fundiu com o PCH e o Centro Nacional de Referências Culturais (CNRC) e se dividiu em um órgão normativo, a Secretaria do Patrimônio Histórico e Artístico Nacional (Sphan) e um órgão executivo, a Fundação Nacional Pró-Memória (FNPM). Conceitualmente, a mudança proposta por Magalhães sintetiza-se na permuta do termo patrimônio histórico e artístico por patrimônio cultural. A ideia era trabalhar a partir do conceito de referências culturais em vez de monumento nacional. Contudo, o passar dos anos mostrou que não houve uma superação conceitual, mas uma sobreposição, e, em alguns casos, uma justaposição desses conceitos9.

Numa recente reflexão na Conferência Magna do I Fórum Nacional de Patrimônio Cultural, o historiador Ulpiano Toledo Bezerra de Meneses (2012) ressaltou que a mudança conceitual provocada por Magalhães e confirmada pela Constituição de 1988 não se caracteriza tanto por uma ampliação do objeto ou dos objetivos dessa política, mas por um deslocamento de sua matriz:

[...] era o poder público que instituía o patrimônio cultural, o qual só se comporia de bens tombados. O tombamento, portanto, tinha papel instituinte do valor cultural - daquele valor que credenciava a inclusão do bem num rol formalmente definido. Ao inverso, a nova Constituição Federal reconheceu aquilo que é posição corrente, há muito tempo, nas ciências sociais: os valores culturais (os valores, em geral)

9. Legalmente, essa permuta é observada anos depois no artigo 216 da Constituição Federal de 1988 e no Decreto no 3.551/200o, enquanto a sobreposição/justaposição é confirmada pela permanência do Decreto-lei no 25/1937. 
não são criados pelo poder público, mas pela sociedade. $\mathrm{O}$ patrimônio é antes de mais nada um fato social - essa afirmação, nos órgãos de preservação, nas décadas de 1970 e 1980, provocava escândalo e alimentava mal-entendidos. (MENESES, 2012, p. 33-34)

Essa mudança de matriz é fundamental para o debate sobre educação e patrimônio, pois, até então, observa-se que a prática educativa era pensada tal como o processo de atribuição de valor (do Estado para a sociedade). Interessa aqui indagar como essa mudança conceitual repercutiu nas práticas e concepções educacionais na época em que foi pautada internamente. Para isso, mostra-se relevante analisar a atuação do CNRC, já que parte do seu corpo técnico e sua base conceitual foram incorporados à recém-criada FNPM.

Criado em 1975, em plena ditadura militar, e formado por um grupo multidisciplinar, esse Centro realizou projetos em diversas áreas temáticas e em diferentes lugares motivados pelo incômodo da falta de reconhecimento e de identidade do produto cultural nacional e pela crença na ideia da cultura local como fonte de desenvolvimento econômico. Todos os seus projetos buscaram fortalecer os conhecimentos e referências culturais locais e, a partir deles, estimular soluções e alternativas criativas e locais para enfrentar, sobretudo, a crise financeira, a pobreza e a homogeneização cultural gerada pela galopante globalização ${ }^{10}$.

O que chama atenção na forma de atuação desse Centro são a proximidade e a participação dos grupos e comunidades locais na elaboração e desenvolvimento dos projetos aliadas a uma concepção dinâmica de

10. Sobre o processo de elaboração e seleção dos projetos realizados pelo CNRC, destaca Fonseca: o processo de elaboração de projetos era informal, pois tanto podiam ser formulados no próprio CNRC como encaminhados por agentes externos. O "guichê" do CNRC atraía pesquisadores independentes e com projetos culturais pouco ortodoxos. Foi o caso dos projetos do Museu ao Ar Livre, de Orleans, SC; da produção de banana-passa, na região fluminense; do uso da marca estampada em folha de flandres, em Juiz de Fora; da fabricação de lixeiras com pneus usados, no nordeste; da construção de modelos matemáticos para a classificação de técnicas do trançado indígena; da impressão em computador dos padrões-repassos, utilizados na tecelagem em teares de quatro pedais, no Triângulo Mineiro etc. A seleção também não obedecia a critérios rígidos, pois o que interessava era o seu potencial - nem sempre percebido pelos autores do projeto, como ocorreu, por exemplo, com o do museu de Orleans -, para o conhecimento de aspectos pouco estudados da realidade brasileira, e em termos de perspectiva de ações inovadoras (FONSECA, 1997, p. 165). 
cultura. Tratava-se de um processo heterogêneo e multidisciplinar baseado na busca conjunta por soluções. Bastante próximo das ideias do filósofo norte-americano John Dewey (2011) e da educação dialógica do pedagogo brasileiro Paulo Freire (2005), a atuação do CNRC envolvia pesquisadores (educadores e educandos) e objetos de pesquisa numa relação solidária e cooperativa de produção e troca de conhecimentos. Ao estimular as manifestações culturais e os conhecimentos locais, esses projetos contribuíam também para a promoção, proteção e desenvolvimento da diversidade cultural não reconhecida pelo Estado ${ }^{11}$.

Ao considerar o patrimônio por um viés cultural e inserir os detentores de referências culturais e seu contexto na política e nas práticas preservacionistas, Aloísio Magalhães alterou o significado de preservar e ampliou a função social dessa política. Nesse sentido, o lema de sua direção - "a comunidade é a melhor guardiã de seu patrimônio"12 - insinuava que a escolha e a definição dos bens culturais a serem preservados, assim como as formas de sua preservação, deveriam ser negociadas com seus detentores. Para isso, seria necessário retirar a lógica autoritária, vertical e autorizada do patrimônio e torná-lo uma política mais permeável e dialógica. Essa transformação conceitual implicava, portanto, em uma mudança de atitude e postura, e requeria a criação de canais e instrumentos dialógicos internos e externos, conferindo assim contornos mais pedagógicos à prática preservacionista.

De certa forma, Aloísio e o CNRC alinhavam-se também às reflexões e propostas colocadas pela Declaração e pelo Manifesto de Amsterdã de 1975, únicos documentos internacionais desse campo que consideram a população detentora dos bens culturais como sujeitos participantes dos

11. Considerando as manifestações pesquisadas como "um momento da trajetória, e não uma coisa estática", Aloísio Magalhães (1985, p. 172) afirmava que "a política paternalista de dizer que o artesanato deve permanecer como tal é uma política errada" e "culturalmente impositiva", pois "o caminho, a meu ver, não é esse; o caminho é identificar isso, ver o nível de complexidade em que está, qual é o desenho do próximo passo e dar estímulo para que ele dê esse passo”. Qualquer intervenção deveria ser precedida, portanto, do conhecimento da especificidade daquele saber-fazer, em sua trajetória e em sua inserção no contexto atual. Consequentemente, as formas de ação deveriam ser necessariamente diferenciadas, adequadas a cada caso e momento, e envolvendo a participação da comunidade que produz e consome aqueles bens, o que descartava, por princípio, o recurso a "receitas" para lidar com a questão do artesanato (FONSECA, 1997, p. 167).

12. Luiz Antônio Bolcato Custódio lembra essa máxima da direção de Aloísio Magalhães no texto "Educação patrimonial: experiências", em BARRETO et al., 2008, p. 24. 
processos de preservação. Ambas apresentam uma abordagem antropológica do patrimônio arquitetônico, compreendendo as edificações e sítios urbanos como suportes materiais de diversas memórias e narrativas. Além disso, ao atribuir um valor educativo às edificações, esses documentos afirmam ser a educação um canal privilegiado para a descoberta, apropriação, interpretação e reutilização desses testemunhos, garantindo assim que o patrimônio arquitetônico seja valorizado por suas memórias e relações (in) formais, individuais e casuais.

Embora caiba aqui refletir sobre as ações e práticas preservacionistas da FNPM, houve, nesse período, duas ações que relacionaram educação e patrimônio cultural e que devem ser analisadas: o projeto interministerial do Ministério da Educação e Cultura (MEC), "Interação entre Educação Básica e os Diferentes Contextos Culturais Existentes no País" (BRANDÃO et al., 1996), e o $1^{\circ}$ Seminário sobre o Uso Educacional de Museus e Monumentos (HORTA et al., 1999).

Segundo a coordenadora de Educação Patrimonial do Iphan, Sonia Florêncio (2012), o Projeto Interação - como ficou conhecido -, mesmo não se denominando educação patrimonial, realizou práticas educativas dialógicas no campo mais amplo da cultura na medida em que buscava aliar e aproximar as práticas da educação básica com os diferentes contextos culturais do Brasil:

O Projeto Interação quis associar a prática escolar rotineira e concreta da educação básica à realidade não menos rotineira e concreta de cada contexto cultural, tal como ele existe e se reproduz, para tornar essa realidade mais acentuada e, criticamente, um instrumento de sua própria transformação, em cada uma de suas comunidades sociais de realização. (FLORÊNCIO, 2012, p. 23)

Tratava-se de um projeto oriundo dos acúmulos do CNRC que teve como objetivos principais incentivar, valorizar e promover a cultura popular por meio da participação da comunidade através de processos educacionais. Entendendo o patrimônio cultural como elemento vivo, dinâmico e constituidor das relações sociais e da vida cotidiana, o Projeto Interação imprimiu outra abordagem ao objeto de trabalho do Iphan, visando assim 
alterar o processo de reificação dos bens culturais que era desenvolvido pelas políticas públicas preservacionistas.

\section{EDUCAÇÃO PATRIMONIAL: ABERTURA DE UM CAMINHO}

Em 1983, por sua vez, FNPM e Museu Imperial de Petrópolis organizaram um seminário que discutiu a relação entre objetos museográficos, monumentos nacionais e educação. $\mathrm{O} 1^{\circ}$ Seminário sobre o Uso Educacional de Museus e Monumentos foi organizado pela museóloga e então diretora deste museu, Maria de Lourdes Parreiras Horta, e reuniu especialistas de várias áreas de formação e atuação de diversas regiões do Brasil. Nesse evento, o termo educação patrimonial foi cunhado e definido baseado na metodologia inglesa da heritage education (HORTA et al., 1999, p. 5).

Ao acabar com quase 50 anos de silêncio no Iphan, o termo educação patrimonial inaugurou um novo lugar da educação na política preservacionista nacional. Embora não tenha superado o (não) lugar e a empiria característicos do primeiro momento, esse termo marca o início de um processo de institucionalização da educação no Iphan que veio a se consolidar na década de 2000.

Sistematizada e apresentada no Guia Básico de Educação Patrimonial em 1999 (HORTA et al.) ${ }^{13}$, a educação patrimonial foi instituída como um instrumento de "alfabetização cultural" com a pretensão de conduzir o indivíduo à leitura do mundo, alimentar nele sentimentos de identidade $\mathrm{e}$ cidadania e reforçar a autoestima individual e coletiva:

Trata-se de um processo permanente e sistemático de trabalho educacional centrado no Patrimônio Cultural como fonte primária de conhecimento e enriquecimento individual e coletivo. A partir da experiência e do contato direto com as evidências e manifestações da cultura, em todos os seus múltiplos aspectos, sentidos e significados, o trabalho da Educação Patrimonial busca levar as crianças e adultos a um processo ativo de conhecimento, apropriação e valorização de sua herança cultural, capacitando-os para um melhor

13. A partir deste ponto vou referir-me ao Guia Básico de Educação Patrimonial (HORTA et al., 1999) apenas como Guia. 
usufruto destes bens, e propiciando a geração e a produção de novos conhecimentos, num processo contínuo de criação cultural. (HORTA et al., 1999, p. 6)

Na fala de abertura do seminário - reproduzida no curso Patrimônio Cultural e Educação, realizado em 2004 na cidade de Goiânia (BARRETO et al., 2004) -, Horta explicou que:

[...] A educação patrimonial desenvolve-se a partir da evidência material, decorre dela. É uma relação de causa e efeito, ao passo que, na escola, o ensino tem um sentido explicativo (na direção efeito-causa): "Quais as causas do Descobrimento do Brasil? Quais as causas da Proclamação da República?” E um sem-fim de causas, quando a criança entra na escola desconhecendo totalmente o que é o Brasil ou um regime político (a maioria nunca ultrapassou a fronteira de seu bairro e já viu o Rei Momo na televisão). O ensino através da evidência tem um sentido indutivo. Segue a direção contrária - causa-efeito. O objeto é o ponto de partida, como realidade básica da qual se pode depreender um universo de informações e considerações. (HORTA in BARRETO et al., 2004, p. 17-18)

Para isso, valeu-se de uma metodologia bastante flexível e bem estruturada aplicável a qualquer bem cultural (material ou imaterial) e em qualquer espaço educacional (formal ou não formal), composta de quatro etapas (observação, registro, exploração e apropriação) que podem ser aplicadas em diferentes atividades educativas ${ }^{14}$. Suas quatro etapas baseiam-se em teorias pedagógicas construtivistas e podem ser empregadas em diversas situações de aprendizagens.

Embora seja eficaz em sua abordagem, observa-se um descompasso entre conceito e metodologia. Na verdade, esse descompasso encontra-se também na sua própria concepção educacional e patrimonial. Mais

14. Esse Guia e o Manual de atividades de educação patrimonial de Evelina Grunberg (2007) apresentam exemplos de atividades educativas com diferentes tipos de objetos museográficos e patrimoniais. As atividades, de acordo ambas as publicações, podem ser realizadas em espaços formais (escolas) e não formais de educação (museus, centros culturais, praças, ruas etc.). 
preocupada com os objetos culturais que com os sujeitos envolvidos nos processos de aprendizagem, tal concepção aproxima-se, assim, das ideias de educação defendidas por Mário de Andrade e Rodrigo Melo Franco de Andrade e da educação bancária denunciada por Paulo Freire (2005).

Com "alfabetização cultural", pretende-se realizar uma ação educativa de transmissão de informações, valores e concepções de mundo de alguns "detentores de conhecimento" para aqueles que nada sabem e que devem ser conscientizados. Tal tipo de ação educativa não condiz, segundo Paulo Freire, com uma ação de conscientização e reforça a fetichização e reificação da cultura denunciada por Meneses (2000, p. 37, apud LEITE, 2007, p. 65) como fonte de alienação permanente. Para Freire, os processos de conscientização e de educação confundem-se na medida em que ambos devem ser encarados como um processo permanente de consciência-mundo e de atitude crítica dos homens em seu contexto espaço-temporal:

[...] A conscientização implica, pois, que ultrapassemos a esfera espontânea da apreensão da realidade, para chegarmos a uma esfera crítica na qual a realidade se dá como objeto cognoscível e na qual o homem assume uma posição epistemológica.

A conscientização é, neste sentido, um teste de realidade. Quanto mais conscientização, mais se des-vela a realidade, mais se penetra na essência fenomênica do objeto, frente ao qual nos encontramos para analisá-lo. Por esta mesma razão, a conscientização não consiste em estar frente à realidade assumindo uma posição falsamente intelectual. A conscientização não pode existir fora da práxis, ou melhor, sem o ato ação-reflexão. Esta unidade dialética constitui, de maneira permanente, o modo de ser ou de transformar o mundo que caracteriza os homens. (FREIRE, 2001, p. 30, grifos do autor)

Ao colocar as evidências materiais (os objetos) como enfoque do processo educativo - e não as pessoas -, aproxima-se de uma ação educativa vertical de convencimento sobre a importância e necessidade de preservar algo. O fim de tal aprendizado não é a conscientização, mas a alienação 
pelo objeto reificado e fetichizado através do esclarecimento (ADORNO; HORKHEIMER, 1985).

No entanto, o problema maior desse Guia está em tomá-lo como um paradigma da educação patrimonial, como única abordagem pedagógica do patrimônio cultural e reproduzi-lo ipsis litteris. Como metodologia pedagógica, ele apresenta muitos pontos positivos, por exemplo: indicações de possibilidades multi e interdisciplinares de abordagem educativa dos bens culturais; aprendizado baseado na experiência e no contato direto com as evidências materiais culturais; inversão do sentido explicativo (de efeito-causa para causa-efeito); estrutura de começo-meio-fim das atividades e da metodologia; e participação dos educandos na construção do conhecimento.

Contudo, os maiores problemas encontram-se em sua concepção, pois, ao ter os bens culturais como enfoque e centro das ações educativas e tomá-los sob uma lógica cartesiana (causa-efeito), corre-se o risco de: não dar atenção ao contexto ou à contextualização dos bens culturais; esconder em sua materialidade os processos de valoração e os fenômenos, práticas, saberes e pessoas que garantem sua existência; e tornar implícita e irrefutável a escolha das narrativas, informações e valores atribuídos aos bens culturais.

Embora tenha rompido o silêncio e a empiria que marcavam a trajetória da educação no Iphan, sua concepção de educação não assegura um processo de conscientização. Para isso, faz-se necessário um processo permanente e sistemático de educação transdisciplinar e comunitária (para além dos muros da escola) que envolva apropriação, uso e gestão coletiva dos bens culturais; um processo no qual as pessoas sejam o centro e os bens culturais, seu tema gerador (FREIRE, 2005).

As formulações do Guia no início da década de 1980 estavam, por sua vez, de acordo com uma série de cartas patrimoniais que, desde 1960, vinham refinando a forma de tratar a educação no campo do patrimônio. Carta de Mar del Plata (1970) e Recomendações da Unesco (1962) sobre a salvaguarda da beleza e do caráter das paisagens e sítios, por exemplo, apontavam a necessidade de haver algum método ou metodologia para as ações educativas, assim como algum material informativo ou pedagógico. Algumas ainda apontam possíveis ações, agentes ou públicos para as ações educativas. Essas cartas, com exceção da Carta de Amsterdã (1975), 
consideram o ensino formal como principal locus das ações educativas e consideram o público-alvo da educação como sujeito passivo.

Ao publicar e difundir esse Guia em 1999, o Iphan confirmou-o como paradigma e "receita" de educação patrimonial. Dessa forma, reafirmou-se a condição de marco zero desse conceito e metodologia denunciada por Mário Chagas (2004). Para esse museólogo, ao se fazer herdeira da heritage education, a educação patrimonial desautorizou as práticas, concepções e debates anteriores e contemporâneos à sua constituição ${ }^{15}$, instituindo uma arena na qual se colocou como hegemônica:

O campo da educação patrimonial não é tranquilo e não é pacífico; ao contrário, é território em litígio, aberto para trânsitos, negociações e disputas de sentidos. Orientações, tendências e metodologias diversas estão em jogo neste território. Toda a tentativa de reduzir a educação patrimonial a uma única metodologia também pode ser lida como tentativa de domínio hegemônico, controle e eliminação de diferenças. Conclusão: a denominada educação patrimonial não é por si só emancipadora ou repressora, fértil ou estéril, transformadora ou conservadora. (CHAGAS, 2004, p. 144-145).

Apesar de a educação patrimonial proposta pelo Guia ser veiculada e muitas vezes aceita como paradigma hegemônico sobre o assunto, observa-se, dentro do órgão, a presença de práticas e concepções diversas que reproduzem o Guia e inventam outras formas e concepções de educação. Essa situação confirma tanto a percepção da educação como prática complementar quanto como território de trânsitos, negociações e disputas salientado por Mário Chagas. As ações e projetos educativos desenvolvidos pelo Iphan ao longo do tempo nunca foram conceitualmente homogêneas, uniformes ou processuais.

\section{OUTROS HORIZONTES PARA A EDUCAÇÃO PATRIMONIAL}

Desde 2004, assiste-se a um novo momento da educação dentro do Iphan

15. "Ao se fazer herdeira da heritage education, a educação patrimonial abriu mão do diálogo possível e possivelmente fértil com os museólogos, antropólogos, sociólogos, psicólogos, filósofos e educadores brasileiros." (CHAGAS, 2004, p. 144.) 
com a criação de uma estrutura institucional (lugar) e de um código orçamentário que se mantêm até os dias atuais. Desde então, observam-se esforços desse setor e de alguns funcionários em se articular com órgãos públicos das três esferas governamentais, movimentos sociais e membros da sociedade civil, com a intenção de debater a função da educação dentro da práxis preservacionista e do Iphan como agente educador.

Em vez de gestar um conceito dentro da instituição, a então Gerência de Educação e Projeto ${ }^{16}$ iniciou um amplo e compartilhado processo de discussões sobre educação patrimonial através dos seguintes espaços e instrumentos: Encontros Nacionais de Educação Patrimonial (2005, São Cristóvão-SE; 2011, Ouro Preto-MG); Rede das Casas do Patrimônio (blog ${ }^{17} \mathrm{e}$ grupo de e-mail); seminários, oficinas e encontros (Oficina para Capacitação em Educação Patrimonial e Fomento a Projetos Culturais nas Casas do Patrimônio, 2008, Pirenópolis-GO; I Seminário de Avaliação e Planejamento das Casas do Patrimônio, 2009, Nova Olinda-CE); e publicações.

Em um texto de balanço sobre o I Encontro Nacional de Educação Patrimonial (Enep), que reuniu funcionários do Iphan, agentes do poder público, da sociedade civil e de movimentos sociais, a arquiteta e urbanista Ana Carmen Amorim Jara Casco (2005) destacou que tal reunião permitiu que fosse revelada uma discrepância entre as iniciativas da sociedade civil e a necessidade de uma ação sistemática do Estado.

De acordo com a arquiteta, desse encontro entre diferentes atores sociais novas perspectivas e potencialidades para a educação patrimonial foram apontadas, por exemplo: a realização de processos educativos democráticos e horizontais que busquem a valorização e a promoção do legado cultural local; a criação de elos de pertencimento entre sociedade e seu contexto; o enriquecimento cultural da comunidade local; o desenvolvimento de canais e mecanismos sociais e políticos de participação dos processos decisórios locais. Ao Estado, caberia criar mecanismos de escuta apurada e canais que possibilitem a participação da sociedade em todo o processo de preservação e salvaguarda do seu patrimônio cultural. Quanto à necessidade institucional de uma política estatal de Educação Patrimonial,

16. Em 2009, com a reforma administrativa do Iphan, a Gerência de Educação e Projeto deu lugar à Coordenação de Educação Patrimonial.

17. Visite: <http://educacaopatrimonial.wordpress.com>. Acesso em: 31 maio 2015. 
foi recomendado que tal política fosse construída por meio de diretrizes "[...] para orientar a ação institucional, e não regular o campo social que precisa ter independência e criatividade próprias para inventar e sugerir trabalhos de educação patrimonial" (CASCO, 2005, p. 2).

Com isso, passou-se a observar algumas mudanças no discurso e em algumas práticas no que até então se entendia como educação patrimonial. A missão do Iphan - proteger e preservar o patrimônio cultural - deixou de ser no discurso o fim das ações educativas e tornaram-se desdobramentos de processos educativos mais amplos que envolviam os bens e as referências culturais locais num processo de transformação social. Dessa forma, a educação patrimonial vem tentando deixar de ser uma metodologia pedagógica centrada na preservação do patrimônio cultural para almejar a formação de cidadãos críticos e autônomos, empoderados de suas referências e bens culturais.

No contexto do I Enep e baseado na experiência da Fundação Casa Grande - Memorial do Homem Kariri (Nova Olinda-CE) ${ }^{18}$-, criou-se o projeto das Casas do Patrimônio, que aliou uma ideia proposta pelo Departamento de Patrimônio Material e Fiscalização (Depam/Iphan) à dificuldade de inserção do tema nos espaços formais de educação. De acordo com a Carta de Nova Olinda, escrita no I Seminário de Avaliação e Planejamento das Casas do Patrimônio em 2009, esse projeto pretende ser: [...] um espaço de interlocução com a comunidade local, de articulação institucional e de promoção de ações educativas, visando fomentar e favorecer a construção do conhecimento e a participação social para o aperfeiçoamento da gestão, proteção, salvaguarda, valorização e usufruto do patrimônio cultural. (CARTA DE NOVA OLINDA, 2009, p. 5)

Entre 2008 e 2009, algumas Casas do Patrimônio foram inauguradas em vários estados do Brasil e se estabeleceram em uma rede virtual de trocas e cooperação. Desde 2013, as Casas do Patrimônio vêm se expandindo pelo território nacional, e a Coordenação de Educação Patrimonial (Ceduc/Iphan) vem apresentando o projeto e desenvolvendo oficinas para

18. Sobre esta fundação, visite: <http://www.fundacaocasagrande.org.br/principal.php $>$. Acesso em: 31 maio 2015. 
sua implantação em diversos municípios e regiões ${ }^{19}$.

As diretrizes de funcionamento e atuação das Casas do Patrimônio (estabelecidas coletivamente na "Oficina de Capacitação em Educação Patrimonial e Fomento a Projetos Culturais nas Casas do Patrimônio" de 2008) esboçam uma perspectiva educativa distinta daquela até então praticada pelo Iphan. Ao enfocar a ação nas comunidades e em suas referências culturais e tomar os princípios da educação dialógica de Paulo Freire, a proposta das Casas do Patrimônio encontra-se em concordância com os debates travados no I Enep.

A elaboração de um conceito de educação patrimonial e de suas diretrizes ocorreu, por sua vez, no II Enep, em julho de 2011. Depois de um período de gestação colaborativa, tal conceito veio a público oficialmente apenas em 2014, com a publicação do caderno Educação patrimonial: histórico, conceitos e processos (FLORÊNCIO et al., 2014):

[...] a Educação Patrimonial constitui-se de todos os processos educativos formais e não formais que têm como foco o patrimônio cultural apropriado socialmente como recurso para a compreensão sócio-histórica das referências culturais em todas as suas manifestações a fim de colaborar para o seu reconhecimento, valorização e preservação. Considera, ainda, que os processos educativos devem primar pela construção coletiva e democrática do conhecimento, por meio do diálogo permanente entre os agentes culturais e sociais e pela participação efetiva das comunidades detentoras das referências culturais onde convivem diversas noções de patrimônio cultural. (FLORÊNCIO et al., 2014, p. 19)

Embora não tenha sido regulamentado pelo órgão ${ }^{20}$, tal conceito revela um esforço técnico e político de propor uma concepção de educação patrimonial baseada no viés antropológico do conceito de patrimônio cultural e

19. Para acompanhar as ações das Casas do Patrimônio e da Rede das Casas do Patrimônio, confira o site: <https://educacaopatrimonial.wordpress.com/>. Acesso em: 3 mar. 2014.

20. Esse conceito compõe uma Portaria que ainda hoje encontra-se "engavetada" no DAF/Iphan. Contudo, a Ceduc publicou, em 2014, Educação patrimonial: histórico, conceitos e processos que contém os debates dos Enep e as novas diretrizes para educação patrimonial. Ver: <http://www. IPHAN.gov.br/baixaFcdAnexo.do?id=4240>. Acesso em: 3 out. 2014. 
na concepção dialógica de educação. Tal escolha carrega um aporte teórico que se aproxima da proposta do projeto Interação (BRANDÃO et al., 1996) e se distancia, por sua vez, da educação patrimonial proposta pelo Guia (HORTA et al., 1999) e pelas concepções de educação defendidas por Mário de Andrade e Rodrigo Melo Franco de Andrade.

Ao considerar o patrimônio cultural apropriado socialmente como tema gerador (FREIRE, 2005), e não como objeto dos processos educativos, propõem-se duas profundas alterações pedagógicas: são as pessoas e suas referências culturais os objetos e objetivos da educação patrimonial, e não mais os bens culturais tombados ou registrados. Dessa forma, recusa-se a lógica bancária da educação em prol da realização de processos educativos dialógicos (FREIRE, 2005), cujos conhecimentos sobre si e sobre o mundo são elaborados pelas pessoas envolvidas tendo em vista uma transformação social, uma melhoria da vida.

A educação patrimonial pretende, assim, deixar de ser um processo unilateral baseado na comunicação/difusão de informações. Dessa maneira, a máxima "conhecer para preservar", que ancorava as concepções educativas bancárias em vigor até então, é colocada em xeque. A confusão entre esses termos gerava e ainda gera, entre outras coisas, uma relação pedagógica que conduz, segundo Paulo Freire, “[...] à escravização das consciências, [na qual] a pedagogia dominante é a pedagogia das classes dominantes" (FREIRE, 2001, p. 89). Nessa nova concepção, educação é defendida como permanente processo de formação do indivíduo em sociedade. Processo que extrapola os lugares tradicionais da educação (escolas, universidades etc.) e passa a ser composto por todos os espaços e momentos de socialização e vida. Por ser parte da vida, os bens culturais apropriados socialmente tornam-se, assim, possibilidade e potencialidade educativa. De acordo com Florêncio, coordenadora de educação patrimonial do Iphan:

[...] a Educação Patrimonial deve ser tratada como um conceito basilar para a valorização da diversidade cultural, para o fortalecimento de identidades e de alteridades no mundo contemporâneo e como um recurso para a afirmação das diferentes maneiras de ser e de estar no mundo. O reconhecimento deste fato, certamente, inserido em um campo de lutas e contradições evidencia a visibilidade de culturas 
marginalizadas ou excluídas da modernidade ocidental, e que são fundamentais para o estabelecimento de diálogos interculturais e de uma cultura de tolerância com a diversidade. (FLORÊNCIO, 2012, p. 24)

Ao basear-se na ideia de referências culturais e no patrimônio cultural apropriado socialmente, tal concepção requer (em suas últimas consequências) que a própria instituição modifique sua postura perante a sociedade. Para que ela se realize, a lógica paternalista e clientelista do Estado deve sucumbir em prol de metodologias técnicas e mecanismos jurídicos e administrativos mais dialógicos e democráticos. Desse modo, a educação patrimonial pode vir a ser um instrumento de contato e diálogo entre comunidades e Iphan na construção de práxis preservacionistas mais comunitárias, compartilhadas e cidadãs. De acordo com Oliveira:

[...] a Ceduc considera a Educação Patrimonial como tema de trabalho transversal e proposta política. No que se refere ao conceito, acredita que são oportunidades para discutir e construir a valorização e proteção do patrimônio cultural. Isso faz com que um amplo espectro de atividades seja considerado Educação Patrimonial. Da mesma forma identifica possibilidade educativa em todas as ações finalísticas do IPHAN. (OLIVEIRA, 2011, p. 28)

Portanto, como tema transversal e proposta política - e não como metodologia -, a educação patrimonial pode, então, vir a ser entendida e defendida não mais como um mero instrumento ou complemento, mas como atividade preservacionista. Nessa perspectiva, cabe ao Iphan querer e conseguir se refazer (ou seja, reformular suas práticas e mecanismos e perturbar sua cultura institucional) e à sociedade civil tomar a política preservacionista como um instrumento político de existência e resistência social e se corresponsabilizar na preservação de seus bens culturais.

Para colocar essa proposta conceitual em prática, faz-se necessária a existência de ações transversais e cooperativas, que envolvam diferentes atores e agentes sociais - órgãos públicos, instituições públicas e privadas, sociedade civil, movimentos sociais e comunidades - em projetos e ações 
conjuntas e/ou corresponsáveis. Nesse sentido, o Iphan vem apostando em três projetos distintos: a rede das Casas do Patrimônio, o Proext (parceria com o MEC iniciada em 2009 que fomenta ações de educação patrimonial no escopo da extensão universitária) e o Programa Mais Educação (parceria com o MEC iniciada em 2011 que insere o tema da educação patrimonial dentro do projeto federal de fomento à educação integral).

\section{DAS ATUALIDADES, PERPLEXIDADES E UTOPIAS}

Ainda é historicamente cedo para traçar alguma análise sobre esses projetos e as formas como o Iphan vem colocando em prática aquilo que está pautando. É preciso que as conjunturas políticas, pactos, encontros e desencontros aconteçam para saber como o verbo se fará em prática.

Contudo, tal concepção de educação patrimonial, por ser dialógica, inspira uma transformação e, consequentemente uma esperança. Aspirase assim uma política preservacionista compartilhada, corresponsável e baseada na participação social e local. Nesse sentido, a esperança aqui alimentada encontra-se em sintonia com os termos do parágrafo $1^{\circ}$ do artigo 216 de nossa Carta Magna de 1988:

O Poder Público, com a colaboração da comunidade, promoverá e protegerá o patrimônio cultural brasileiro, por meio de inventários, registros, vigilância, tombamento e desapropriação, e de outras formas de acautelamento e preservação.

Reconhecer as pessoas e as comunidades como detentoras de suas referências e bens culturais implica subverter a lógica clientelista, paternalista e tecnicista que pauta a relação entre Iphan e sociedade desde 1937. Essa lógica atravessa o funcionamento de todo aparelho estatal brasileiro, legitima a exclusividade do Estado sobre a esfera pública e alija os cidadãos da vida pública.

Embora este artigo tenha como objeto de análise a educação dentro do IPHAN, o arquiteto do Centro de Preservação Cultural da Universidade de São Paulo (CPC-USP), Gabriel de Andrade Fernandes (2014/2015), ao participar do VI Fórum de Mestres e Conselheiros em Minas Gerais, observou uma discrepância política/pedagógica nas ações de educação patrimonial apresentadas no fórum e apontou que

[...] é ainda recorrente a noção de educação como atividade 
meramente informativa - ou, pior, como atividade disciplinadora da relação dos sujeitos com os bens culturais. É neste último sentido que talvez ainda sejam necessárias novas discussões e pesquisas: em que medida os problemas de coerção dos sujeitos e de imposição de valores são específicos de uma ação educativa mal formulada, ou são específicas do próprio campo do patrimônio cultural como política pública? (FERNANDES, 2014/2015, p. 163-164)

Ainda é recorrente a realização de ações educativas informativas e disciplinadoras e são vários os seus agentes: órgãos governamentais, empresas, organizações da sociedade civil etc. Portanto, no momento que o próprio órgão preservacionista federal aponta e aposta em uma concepção educativa dialógica, transversal e coletiva, faz-se necessário estar atento às práticas institucionais que dela decorrem.

Faz-se necessário também divulgar, discutir, compreender e apropriar-se desse novo conceito e se valer de seu respaldo institucional para alcançar a política preservacionista e fazer dela, cada vez mais, uma política pública cultural de transformação e resistência político-social, de afirmação da diversidade sociocultural e de autoformação de cidadãos empoderados de suas referências e bens culturais, críticos e autônomos.

\section{REFERÊNCIAS}

ADORNO, Theodor W; HORKHEIMER, Max. Dialética do esclarecimento: fragmentos filosóficos. Rio de Janeiro: Jorge Zahar, 1985.

ANDRADE, Mário de. A capela de Santo Antônio. Revista do Serviço do Patrimônio Histórico e Artístico Nacional, Rio de Janeiro, ํㅡㄴ 1, 1937.

______́ri . Uma carta do padre Jesuíno do Monte Carmelo. Revista do Serviço do Patrimônio

Padre Jesuíno do Monte Carmelo. Rio de Janeiro: MEC; Sphan, 1945.

. Anteprojeto para criação do Serviço do Patrimônio Artístico Nacional. Revista do Patrimônio Histórico e Artístico Nacional, Brasília, DF, no 30, p. 271-287, 2002.

ANDRADE, Rodrigo Melo Franco de. Programa. Revista do Serviço do Patrimônio Histórico e Artístico Nacional, Rio de Janeiro, v. 1, p. 3-4, 1937. 
. Rodrigo e o Sphan: coletânea de textos sobre o patrimônio cultural. Rio de Janeiro: Ministério da Cultura; Fundação Nacional Pró-Memória, 1987.

BARRETO, Euder Arrais; ZARATIM, Joel Ribeiro; FREIRE, Lídia Freire; BEZERRA, Márcia; CIAXETA, Maria Joana Cruvinel; D’OSVUALDO, Vera Lúcia Abrantes (Org.). Patrimônio cultural e educação: artigos e resultados. Goiânia: UFGO, 2008.

BRANDÃO, Carlos Rodrigues et al. O difícil espelho: limites e possibilidades de uma experiência de educação e cultura. Rio de Janeiro: Iphan; DEPRON, 1996.

BRASIL. Constituição da República Federativa do Brasil. Brasília, DF, 1988. Disponível em: $<$ http://www.planalto.gov.br/ccivil_03/constituicao/constitui\%C3\%A7ao.htm>. Acesso em: 18 jan. 2013.

Decreto-Lei $n^{0}$ 25, de 30 de novembro de 1937. Rio de Janeiro, 1937. Disponível em: <http://www.planalto.gov.br/ccivil_03/decreto-lei/deloo25.htm>. Acesso em: 18 jan. 2013.

. Decreto nº 3.551, de 4 de agosto de 200o. Brasília, DF, 20oo. Disponível em: <http:// www.planalto.gov.br/ccivil_03/decreto/D3551.htm>. Acesso em: 18 jan. 2013.

CASCO, Ana Carmem Amorim Jara. Sociedade e educação patrimonial. 2005. Disponível em: <http://portal.IPHAN.gov.br/portal/baixaFcdAnexo.do?id=526>. Acesso em: 15 ago. 2011.

CHAGAS, Mário. Há uma gota de sangue em cada museu: a ótica museológica de Mário de Andrade. Cadernos de Sociomuseologia, Lisboa, noㅜ 13, 1998.

Diabruras do Saci: museu, memória, educação e patrimônio. MUSAS - Revista Brasileira de Museus e Museologia, Rio de Janeiro, v. 1, no 1, 2004.

DEWEY, John. Experiência e educação. 2ª ed. Petrópolis, RJ: Vozes, 2011.

FERNANDES, Gabriel de Andrade. Notas sobre o VI Fórum de Mestres e Conselheiros - "Os desafios da educação patrimonial" (Belo Horizonte, 4-6 de junho de 2014). Revista do CPC, São Paulo, no 18, p. 159-164, dez. 2014-abr. 2015. Disponível em: <http://www.revistas.usp.br/cpc/ article/view/87792 >. Acesso em: 1 mar. 2015.

FLORÊNCIO, Sônia Regina Rampim. Educação patrimonial: um processo de mediação. In: TOLENTINO, Átila (Org.). Educação patrimonial: reflexões e práticas. João Pessoa: Superintendência do Iphan na Paraíba, 2012, p. 22-29.

FLORÊNCIO, Sônia Regina Rampim; CLEROT, Pedro; BEZERRA, Juliana; RAMASSOTE, Rodrigo. Educação patrimonial: histórico, conceitos e processos. Brasília, DF: Iphan; DAF; COGEDIP; Ceduc, 2014. Disponível em: <http://www.IPHAN.gov.br/baixaFcdAnexo. do? id=4240 $>$. Acesso em: 16 fev. 2014.

FONSECA, Maria Cecília Londres. O patrimônio em processo: trajetória da política federal de preservação no Brasil. Rio de Janeiro: Editora UFRJ; MinC; Iphan, 1997.

FREIRE, Paulo. Conscientização: teoria e prática da libertação: uma introdução ao pensamento de Paulo Freire. $3^{\underline{a}}$ ed. São Paulo: Centauro, 2001.

. Pedagogia do oprimido. São Paulo: Paz e Terra, 2005.

GONÇALVES, José Reginaldo Santos. A retórica da perda: os discursos do patrimônio cultural 
no Brasil. Rio de Janeiro: Editora UFRJ; Iphan, 2002.

GRUNBERG, Evelina. Manual de atividades de educação patrimonial. Brasília, DF: Iphan, 2007.

HORTA, Maria de Lourdes Parreiras; GRUNBERG, Evelina; MONTEIRO, Adriane Queiroz. Guia básico de educação patrimonial. Brasília, DF: Iphan; Museu Imperial, 1999.

I SEMINÁRIO de Avaliação e Planejamento das Casas do Patrimônio. Carta de Nova Olinda. Casas do Patrimônio. Nova Olinda, CE: Iphan, 2009. Disponível em: <http://portal.IPHAN. gov.br/portal/baixaFcdAnexo.do?id=1651>. Acesso em: 15 ago. 2011.

LEITE, Rogério Proença. Contra-usos da cidade: lugares e espaço público na experiência urbana contemporânea. Campinas; Aracaju: Editora da Unicamp; Editora UFS, 2007.

MENESES, Ulpiano Toledo Bezerra de. O campo do patrimônio cultural: uma revisão de premissas. In: IPHAN. I Fórum Nacional do Patrimônio Cultural: Sistema Nacional de Patrimônio Cultural: desafios, estratégias e experiências para uma nova gestão, Ouro Preto/MG, 2009. Brasília, DF: Iphan, 2012, p. 25-39. (Anais; v. 2, t. 1).

OLIVEIRA, Cléo Alves Pinto de. Educação patrimonial no Iphan. 2011. Monografia (Especialização) - Escola Nacional de Administração Pública, Brasília, 2011.

RUBINO, Silvana. A memória de Mário. Revista do Patrimônio Histórico e Artístico Nacional, Brasília, DF, nº 30, p. 138-154, 2002.

SILVA, Fernando Fernandes da. Mário e o patrimônio: um anteprojeto ainda atual. Revista do Patrimônio Histórico e Artístico Nacional, Brasília, nº 30, p. 129-137, 2002.

RECEBIDO EM: 06/03/2015

APROVADO EM: 21/05/2015

\section{FERNANDO PASCUOTTE SIVIERO}

Bacharel e licenciado em História pela Universidade Estadual de Campinas (Unicamp) e mestre em Preservação do Patrimônio Cultural pelo Instituto do Patrimônio Histórico e Artístico Nacional (Iphan). Atualmente é educador na Escola Politeia. E-mail: fpsiviero@yahoo.com.br. 